\title{
Comparative evaluation of different cost effective ovulation induction drugs and their effect on follicular growth, endometrial thickness and pregnancy outcome
}

\author{
Madhumithaa Narayanan*, Uruj Jahaan, Neena Gupta
}

Department of Obstetrics and Gynecology, GSVM Medical College, Kanpur, Uttar Pradesh, India

Received: 19 August 2019

Accepted: 30 September 2019

\section{*Correspondence:}

Dr. Madhumithaa Narayanan,

E-mail: madhu26292@gmail.com

Copyright: () the author(s), publisher and licensee Medip Academy. This is an open-access article distributed under the terms of the Creative Commons Attribution Non-Commercial License, which permits unrestricted non-commercial use, distribution, and reproduction in any medium, provided the original work is properly cited.

\begin{abstract}
Background: Ovulatory dysfunction is a common cause of female infertility, occurring in up to 20 - $30 \%$ of infertile women. The most commonly prescribed ovulation drugs are clomiphene citrate (CC), tamoxifen, aromatase inhibitors (such as letrozole) and gonadotropins. Objective of the study was to evaluate the efficacy of clomiphene citrate, letrozole and tamoxifen for ovulation induction in anovulatory infertility.

Methods: Randomized open label interventional clinical trial. Patients were randomized to 3 drug groups. After baseline investigations, they were subjected to ovulation induction and then USG monitoring of follicular growth and ovulation. The primary outcome measured was occurrence of conception. Secondary outcome was effect on endometrial thickness and ovulation rate.

Results: In the study, letrozole group showed $100 \%$ mono-follicular response. Mid cycle endometrial thickness in about $17 \%$ of cases in CC group is $\leq 8 \mathrm{~mm}$. But all the cases in tamoxifen and letrozole group have ET $>8 \mathrm{~mm}$. This difference is statistically significant. The ovulation and conception rates are highest in letrozole group but the difference was not statistically significant.

Conclusions: Letrozole produces higher mid cycle endometrial thickness, $100 \%$ mono follicular development than clomiphene and tamoxifen. This difference is found to be statistically significant. Ovulation rate and conception rate is highest in letrozole group. But there is no statistically significant difference among the three drugs.
\end{abstract}

Keywords: Anovulatory infertility, Clomiphene citrate, Follicular growth, Letrozole, Ovulation rate, Ovulation induction, Tamoxifen

\section{INTRODUCTION}

Infertility is defined as one year of unprotected intercourse without conception. ${ }^{1}$ Causes of infertility and prevalence in different regions are diverse. Ovulatory dysfunction is a common cause of female infertility, occurring in up to 20-30 percent of infertile women. ${ }^{2}$ When anovulation is the only factor causing infertility, the prognosis is usually good because modern ovulation induction strategies are highly effective. The most commonly prescribed ovulation drugs are clomiphene citrate (CC), tamoxifen, aromatase inhibitors (such as letrozole) and gonadotropins (FSH, LH, human menopausal gonadotropin (hMG), chorionic gonadotropin (hCG). Other medicines used in ovulation induction include bromocriptine, cabergoline, GnRH, GnRH analogs, and insulin-sensitizing agents, which have very specialized applications. Aim of the study was to evaluate the efficacy of clomiphene citrate, letrozole and tamoxifen for ovulation induction in anovulatory infertility. 


\section{METHODS}

Study was randomized open label interventional clinical trial. The primary outcome measured was occurrence of conception. Secondary outcome was effect on endometrial thickness and ovulation rate. Following are the criteria that were used to select patients for the study.

\section{Inclusion criteria}

- Patients with anovulatory infertility

- Patients with unexplained infertility.

\section{Exclusion criteria}

- Male factor infertility

- Infertility due to systemic endocrine disorders like hypothyroidism

- Hypogonadotropic hypogonadism

- Ovarian failure

- Tubal factor causing infertility

- Anatomical causes

All the patients in the study were divided into 3 study groups. (Group 1 - clomiphene citrate, group 2 tamoxifen, group 3 - letrozole) the following baseline investigations were done - baseline USG with antral follicular count, ET, any residual cyst, complete hemogram, ESR, monteux test, random blood sugar, serum TSH, D2/D3 - serum FSH levels, serum AMH and prolactin levels, HSG, semen analysis in male partner, endometrial biopsy for histopathology and AFB staining, TB PCR (in indicated cases).

All the three drugs were administered to the respective group of patients through a fixed regimen which is elaborated in Table 1.

The drugs were started from day $2 / 3$ of cycle and given for 5 consecutive days. Transvaginal USG from day 8 (done on alternative days till ovulation) was done for the purpose of monitoring the following parameters endometrial thickness, dominant follicular size, occurrence of ovulation.

Table 1: Regimen of ovulation induction drugs used in the study.

\begin{tabular}{|llll|}
\hline $\begin{array}{l}\text { Drug } \\
\text { Clomifene } \\
\text { Citrate }\end{array}$ & $\begin{array}{l}\text { Starting } \\
\text { dose }\end{array}$ & Max. dose & $\begin{array}{l}\text { Max. } \\
\text { cycles }\end{array}$ \\
\hline Tamoxifen & $\begin{array}{l}40 \mathrm{mg} \\
(20 \mathrm{mg} \mathrm{BD})\end{array}$ & $\begin{array}{l}150 \mathrm{mg} \text { OD } \\
(40 \mathrm{~g} \mathrm{BD})\end{array}$ & 3 \\
\hline Letrozole & $2.5 \mathrm{mg}$ OD & $5 \mathrm{mg} \mathrm{OD}$ & 3 \\
\hline
\end{tabular}

\section{RESULTS}

- The patients in all 3 groups are equally distributed according to age, socio economic class, BMI, antral follicular count, serum AMH and serum FSH. This is confirmed by chi square test

- In the study, letrozole group showed $100 \%$ monofollicular response

- Mid cycle endometrial thickness in about $17 \%$ of cases in CC group is $\leq 8 \mathrm{~mm}$. But all the cases in tamoxifen and letrozole group have ET $>8 \mathrm{~mm}$. This difference is statistically significant

- Mean endometrial thickness on D16 is higher in letrozole group than the other 2 groups

- The ovulation and conception rates are highest in letrozole group but the difference was not statistically significant.

\section{DISCUSSION}

Tables 2 and 3 show that three study groups were comparable in terms of age of the patients, socioeconomic class, BMI, day 3 serum FSH, antral follicular count and serum AMH values.

Table 2: comparison of socio demographic profile of patients of 3 groups.

\begin{tabular}{|llllllllll|}
\hline Groups & Age & & \multicolumn{1}{c}{ S.E.C } & & & BMI & Normal & Over wt, obese \\
\hline CC & $\mathbf{2 5}$ & $\mathbf{2 6 - 3 0}$ & $\mathbf{> 3 0}$ & Upper & Mid & Lower & Under & Norma & 15 \\
\hline TAM & 8 & 26 & 1 & - & 10 & 25 & 1 & 19 & 8 \\
\hline LET & 5 & 14 & 1 & - & 6 & 14 & 1 & 11 & 14 \\
\hline P-value & 8 & 25 & 2 & - & 11 & 24 & 1 & 20 & 14 \\
\hline
\end{tabular}

Table 3: Comparison of clinical characteristics of patients of 3 groups.

\begin{tabular}{|c|c|c|c|c|c|c|c|c|c|}
\hline \multirow{2}{*}{ Groups } & \multicolumn{3}{|l|}{$\mathrm{AFC}$} & \multicolumn{3}{|c|}{ Sr.AMH (ng/ml) } & \multicolumn{3}{|c|}{ D3 FSH (mIU/ml) } \\
\hline & $<\mathbf{1 0}$ & $10-15$ & $>16$ & $<1$ & 1-3.5 & $>3.5$ & $<10$ & $10-15$ & $>15$ \\
\hline $\mathrm{CC}$ & 5 & 17 & 12 & 2 & 17 & 16 & 26 & 8 & 1 \\
\hline TAM & 3 & 11 & 6 & 1 & 11 & 5 & 15 & 5 & - \\
\hline LET & 6 & 19 & 10 & 2 & 18 & 15 & 25 & 9 & 1 \\
\hline P-value & 0.984 & & & 0.8 & & & 0.947 & & \\
\hline
\end{tabular}


Table 4: Effect of 3 drugs on follicular growth and endometrial thickness.

\begin{tabular}{|lllllll|}
\hline Groups & Follicular growth & D16 ET & & & Mean ET \\
\hline CC & Mono & Multi & $<\mathbf{~ m m}$ & $\mathbf{8 - 1 0} \mathbf{~ m m}$ & $\mathbf{> 1 0} \mathbf{~ m m}$ & \\
\hline TAM & $32(91.5 \%)$ & $3(8.5 \%)$ & $6(17 \%)$ & $27(77 \%)$ & $2(6 \%)$ & $8.77 \pm 0.96 \mathrm{~mm}$ \\
\hline LET & $19(95 \%)$ & $1(5 \%)$ & - & $4(20 \%)$ & $16(80 \%)$ & $10.4 \pm 0.45 \mathrm{~mm}$ \\
\hline P-value & $35(100 \%)$ & $0(0 \%)$ & - & $3(8.5 \%)$ & $32(91.5 \%)$ & $11.2 \pm 0.76 \mathrm{~mm}$ \\
\hline
\end{tabular}

Table 5: Ovulation and conception rates of patients of 3 groups.

\begin{tabular}{|llll|}
\hline Groups & $\begin{array}{l}\text { Ovulation } \\
\text { rate }\end{array}$ & $\begin{array}{l}\text { Conception } \\
\text { rate }\end{array}$ & $\begin{array}{l}\text { Ovulation } \\
\text { conception ratio }\end{array}$ \\
\hline CC & $71.4 \%$ & $20 \%$ & 3.57 \\
\hline TAM & $70 \%$ & $15 \%$ & 4.6 \\
\hline LET & $74.2 \%$ & $31.5 \%$ & 2.3 \\
\hline P-value & 0.935 & 0.32 & - \\
\hline
\end{tabular}

Table 4 shows the percentage of patients showing mono follicular and multi follicular response in the 3 study drugs. In present study, letrozole group showed monofollicular development in $100 \%$ of cases. But CC and tamoxifen showed multi-follicular development in $8.5 \%$ and $5 \%$ cases respectively. Similar to the results, study by Richard S et al also showed a lesser multiple pregnancy rate in letrozole group (3.4\%) than in CC group (7.4\%) But Kar S study showed $100 \%$ mono follicular response in both $\mathrm{CC}$ and letrozole group.,

Table 4 also shows the mean endometrial thickness on day 16 in the 3 drug groups. It was higher in letrozole group $(11.2 \mathrm{~mm})$ than the other 2 groups (CC-8.77 mm and tamoxifen $-10.4 \mathrm{~mm}$ ). It also showed that mid cycle endometrial thickness in about $17 \%$ of cases in CC group was $\leq 8 \mathrm{~mm}$. But all the cases in tamoxifen and letrozole group had ET $>8 \mathrm{~mm}$. Application of chi-square test shows that this difference was statistically significant.

Similar results were seen in a study by Sujata Kar showed that the mean endometrial thickness was slightly higher in letrozole group, 7.65 \pm 2.1 compared to CC 7.61 \pm 1.96 . Similarly, Mitwally and Casper found letrozole was associated with a greater endometrial thickness than other drugs. Badawg et al, study of 438 patients with 1063 cycles, one of the largest studies comparing CC and letrozole, reported significantly higher endometrial thickness in CC group (9.2 \pm 0.7$)$ versus letrozole (8.1 $\pm 0.2, \quad \mathrm{P}=0.021){ }^{4-6}$

They attributed this effect to greater number of mature follicles and higher serum $\mathrm{E}_{2}$ levels. The Table 5 showed the ovulation rate of 3 drugs in the study. Ovulation rate was found to be higher for letrozole $(74.2 \%)$ than the other 2 drugs (CC - 71.4\% and Tamoxifen - 70\%). But this difference was not statistically significant.
The result of the study was comparable to that of many previous studies. A study by M. Zeinalzadeh et al showed an ovulation rate of $72 \%$ in clomiphene citrate and $86 \%$ in letrozole group. A study done by Sujata Kar, to compare Letrozole and clomiphene citrate as first line ovulation induction drug showed ovulation rate was $60.78 \%$ in CC group and $73.08 \%$ in Letrozole group. ${ }^{4,7}$ One study by Badawg et al showed an ovulation rate of $64 \%$ in CC group and $51.6 \%$ in tamoxifen group.., 6

Table 5 also showed the conception rate of 3 drugs in the study. Conception rate was higher for letrozole $(31.5 \%)$ than the other 2 drugs (CC- $20 \%$ and tamoxifen - 15\%). But this difference was not statistically significant.

Similar results were seen in a study by Sujata Kar where pregnancy rate per cycle was astonishingly high with letrozole (21.56\%) than CC (7.84\%). Whereas, Badawg et al, with 438 women (1063 cycles), reported slightly better pregnancy rate in $\mathrm{CC}$ group $(15.1 \%$ in letrozole and $17.9 \%$ in CC group). ${ }^{4-6}$ Bayer et al, with 74 women, Zeinalzaden et al with 107 women, both reported slightly better pregnancy rates with letrozole; however, no statistically significant difference between the two groups. $^{7,8}$ Seyedoshohadaei $\mathrm{F}$ et al reported that pregnancy rate was significantly higher with clomiphene then tamoxifen and letrozole. ${ }^{9}$ A meta-analysis by $\mathrm{He}$ and Jiang, compared letrozole and clomiphene for ovulation induction in PCOS women. ${ }^{10}$ Six RCTs involving 841 patients were analyzed. This showed no significant differences in pregnancy rate between the two groups.

In the study, ovulation: conception ratio was higher in clomiphene citrate (3.5) and tamoxifen (4.6). It was comparatively lower in the letrozole (2.3) group. Clomiphene citrate was introduced half a century ago and still it was one of the most commonly used agents in ovulation induction. However, one major limiting factor with use of clomiphene citrate was that the pregnancy rates were not as good as ovulation rates.

It was concluded by many previous trials that lack of conception despite evidence of ovulation may be due to anti estrogenic effects of clomiphene citrate on the endometrium, which may manifest as a thin endometrium. But tamoxifen and letrozole were devoid of these anti estrogenic effects. So, theoretically the 
discrepancy between ovulation and conception should be lesser in tamoxifen and letrozole than in CC group.

\section{CONCLUSION}

The study concludes that letrozole produces higher mid cycle endometrial thickness, $100 \%$ mono follicular development than clomiphene and tamoxifen. This difference is found to be statistically significant. Ovulation rate and conception rate is highest in letrozole group. But there is no statistically significant difference among the three drugs. Further large scale studies are suggested to be undertaken to confirm these findings.

\section{Funding: No funding sources}

Conflict of interest: None declared

Ethical approval: The study was approved by the Institutional Ethics Committee

\section{REFERENCES}

1. Practice Committee of the American Society for Reproductive Medicine. Definitions of infertility and recurrent pregnancy loss. Fertil Steril. 2008;90:60.

2. Fritz, A Marc, Speroff L. Clinical gynecologic endocrinology and infertility. $8^{\text {th }}$ Ed. Philadelphia: Wolters Kluwer Health/Lippincott Williams and Wilkins; 2011.

3. Richard S, Legro MD, Robert G, Brzyski MD, Michael P, Diamond MD. Letrozole versus clomiphene for infertility in the polycystic ovary syndrome. N Engl J Med. 2014;371:119-29.

4. Kar S. Clomiphene citrate or letrozole for ovulation induction in women with polycystic ovarian syndrome: a prospective randomized trial. Fertil Steril. 2009;92(3):849-52.

5. Mitwally MFM, Casper RF. Use of an AI for induction of ovulation in patients with an inadequate response to clomiphene citrate. Fertil Steril. 2001;75:305-9.

6. Badawg A, Aal IA, Abulalta M. Climiphene citrate or letrozole for ovulation induction in women with polycystic ovarian syndrome: A prospective randomized trial. Fertil Steril. 2009;92:849-52.

7. Zeinalzadeh M, Basirat Z, Esmalpour M. Efficacy of letrozole in ovulation indication compared to that of clomiphene citrate in patients with polycystic ovarian syndrome. J Reprod Med. 2010;55:36-40.

8. Bayar U, Tanriverdi HA, Aykut B, Ayoglu F, Ozcan $\mathrm{O}$, Erdal K. Letrozole vs clomiphene citrate in patients with ovulatory infertility. Fertil Steril. 2006;85:1045-8.

9. Seyedoshohadaei F, Zandvakily F, Shahgeibi S. Comparison of the effectiveness of clomiphene citrate, tamoxifen and letrozole in ovulation induction in infertility due to isolated unovulation. Iran J Reprod Med. 2012;10(6):531-6.

10. He D, Jiang F. Meta- analysis of letrozole versus clomiphene citrate in polycystic ovary syndrome. Reprod Biomed Online. 2011;23:91-6.

Cite this article as: Narayanan M, Jahaan U, Gupta $\mathrm{N}$. Comparative evaluation of different cost effective ovulation induction drugs and their effect on follicular growth, endometrial thickness and pregnancy outcome. Int J Reprod Contracept Obstet Gynecol 2019;8:4549-52. 